\title{
Microspheres of Biodegradable Block Copolymer for Long-Acting Controlled Delivery of Contraceptives
}

\author{
Dedicated to the Memory of the late Professor Ichiro Sakurada \\ C. X. SONG, ${ }^{\dagger}$ H. F. SUN, and X. D. FENG* \\ Institute of Biomedical Engineering, Chinese Academy of Medical Sciences, \\ P. O. Box 25(204), Tianjin, China \\ * Department of Chemistry, Peking University, \\ Beijing, China
}

(Rẹceived November 28, 1986)

\begin{abstract}
Microspheres containing Norgestrel (MCN) were prepared from block copolymer of $\varepsilon$-caprolactone and DL-lactide (PCL- $b$-PLA) through solvent-evaporation process. The MCN produced at $10^{\circ} \mathrm{C}$ using soluble or wettable solvent bears fine and close surface which endows it a higher ability to control drug release. The block copolymer showed a double release mechanism-diffusion release contributed by PCL segment and erosion-caused release by PLA segment. The effects of these two pathways can be balanced by tailoring the ratio of CL/LA in PCL$b$-PLA to such an extent that the erosion-caused release could just compensate the declined amount resulted from diffusion release and a whole zero-order kinetics can be actually achieved. Such a balance has been accomplished when the ratio of $60 / 40$ is used which proved to be a promising controlled delivery system.
\end{abstract}

KEY WORDS Contraceptive Microspheres / Biodegradable Block Copolymer / Long-Acting Controlled Delivery System / Zero-Order Release / Diblock Copolymer / Poly( $\varepsilon$-caprolactone)-b-poly(DL-lactide) /

Over the past decade, biodegradable polymers have been widely studied as various short-term implanted devices. One of the potential applications is medical uses is to build sustained drug delivery system on which many developments have been made. Jackaniz, ${ }^{1}$ Yolles, ${ }^{2}$ and Beck et al. ${ }^{3)}$ studied the so called long-acting contraceptive devices using polylactides (PLA) as carrier. Polin 4 used copolymers of aminoacid as carrier. Pitt et al..$^{5}$ studied many aliphatic polyester and found that poly ( $\varepsilon$-caprolactone) (PCL) possessed expected drug-permeability but with very slow biodegradation. A random copolymer of CL and LA was made to improve pliability but always with fast degradability. Both PCL and its random copolymer with LA used to make capsules containing contracentives. Although all these preparations showed a relatively longterm controlled release in animal tests, yet none of them has been used practically to date. Among other things, the decline of the release rate is one of the main problems. In order to search some other way to face the problem, a series of block copolymers of $\varepsilon$-caprolactone and DL-lactide (PCL- $b$-PLA) was synthesized in our laboratory and showed some peculiarities. Its important character for medical uses is the microphase separation morphology which endows it with a controllable variability in degradation rate and also the drug release rate. In this paper we report the prepa-

\footnotetext{
${ }^{\dagger}$ Present address: c/o Dr. C. G. Pitt, RTI, P.O. Box 12194, Research Triangle Park, N.C. 27709, U.S.A.
} 
ration of injectable microsphere based on the block copolymer PCL- $b$-PLA with proposed mechanism for its zero-order release rate.

\section{EXPERIMENTAL}

\section{Materials}

The block copolymers were synthesized according to our previous method. ${ }^{6}$ All the above block copolymer samples were adjusted to almost the same molecular weight but different segment ratio of CL/LA so that an effective comparison could be made only based on ratio factor.

The drug used in this work is Norgestrel, a woman's contraceptive being used in clinical as daily or monthly scriptions.

Microspheres containing Norgestrel (MCN) were prepared by the solvent-evaporation process introduced by N.R Beck et al. ${ }^{3}$ with some modifications.

\section{Measurement of Drug-Load in MCN}

The microspheres are extracted with methanol for $5 \mathrm{~h}$ with a Fat Extractor. After the methanol is distilled out from the extractive phase, the extracted drug is dissolved in certain amount of absolute ethanol and measured UV spectrometrically.

\section{In Vitro Drug Release Evaluation}

Fast Comparison Test. In order to compare the release behavior of a series of samples within relatively short time, $20 \%$ aqueous solution of ethanol is used as release medium. Each sample is immersed into a given amount of ethanol solution which is maintained at $37^{\circ} \mathrm{C}$ under constant stirring. The amount of drug released is measured by UV spectrometer at regular intervals of time.

Long-Term Release Test. For long-term release, distilled water is used as release medium instead $20 \%$ ethanol. The release medium is collected daily and the drug released into the medium is extracted out with chloroform and
Table I. The general formula and physical parameters of PCL- $b$-PLA

\begin{tabular}{cccccc}
\multicolumn{3}{c}{$\left.\left.\mathrm{RO}\left[\mathrm{CO}\left(\mathrm{CH}_{2}\right)_{5} \mathrm{O}\right]_{n}\right] \mathrm{COCH}\left(\mathrm{CH}_{3}\right) \mathrm{O}\right]_{m} \mathrm{H}$} \\
\hline \multirow{3}{*}{$\begin{array}{c}\text { Sample } \\
\text { code }\end{array}$} & $\begin{array}{c}\text { Monomer ratio } \\
\mathrm{CL} / \mathrm{LA}\end{array}$ & & \multicolumn{2}{c}{ Copolymer properties } \\
\cline { 2 - 3 } \cline { 5 - 6 } & $\mathrm{mol}$ & & {$[\eta]$} & $\bar{M}_{n} \times 10^{-4}$ & $\mathrm{mp} /{ }^{\circ} \mathrm{C}$ \\
\cline { 5 - 6 } C-02 & $90 / 10$ & & 0.60 & 4.1 & 60 \\
C-06 & $75 / 25$ & & 0.59 & 4.0 & 60 \\
C-05 & $60 / 40$ & & 0.59 & 4.0 & 60 \\
\hline
\end{tabular}

measured UV spectrometrically.

\section{RESULTS AND DISCUSSION}

\section{Preparation on $M C N$}

Process conditions and results for the preparation of MCN are listed in Table II. The obtained microspheres contain about $20 \%$ drug load with $90 \%$ in the recovery of $\mathrm{MCN}$ and $95 \%$ in drug-enclose efficiency. The shape of microsphere is mainly affected by the solvent used and the operation temperature. The microsphere prepared at $10^{\circ} \mathrm{C}$ has a compact spherical body with fine and close surface as shown in Figure 1. It bears rather narrow size distribution with major size range from 80 to $120 \mu \mathrm{m}$ which is suitable for injection (see Figure 2). When the operation temperature is elevated to $20^{\circ} \mathrm{C}$, some cracks and splits appeared on the surface of the sphere. If $35^{\circ} \mathrm{C}$ is used, no microsphere but irregular granule with big holes will be obtained (see Figure 3). From Table II, it is seen that when benzene which is neither soluble nor wettable for the drug is used, the drug-enclose efficiency would be greatly reduced. Although increasing the amount of acetone in acetone-chloroform mixture can speed up the sphere-forming, but it would lead to a terribly defective product like the one produced at $35^{\circ} \mathrm{C}$. Figure 4 shows that the release rate of Norgestrel from the $\mathrm{MCN}$ prepared at $10^{\circ} \mathrm{C}$ is more slowly but steadily than the other temperatures. In order to prepare $\mathrm{MCN}$ with some perfect structure 


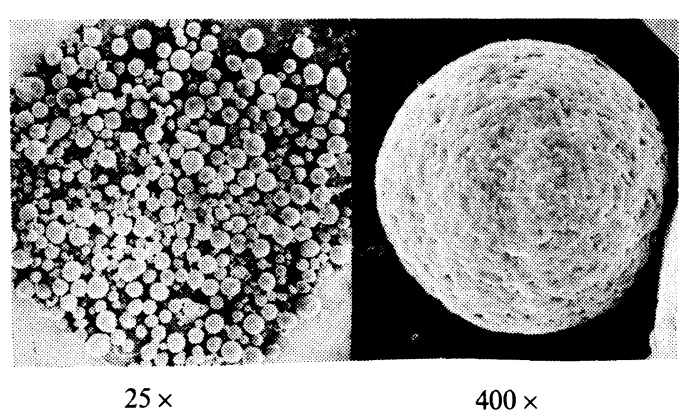

Figure 1. Scanning electron micrograph of MCN prepared at $10^{\circ} \mathrm{C}$. and the expected ability to control drug release, it is important to use a solvent which is both soluble and wettable for the drug and to evaporate the solvent slowly at lower temperature.

\section{Release Mechanism of PCL-b-PLA Micro- sphere \\ Long-term release of Norgestrel from MCN} of different block lengths in PCL- $b$-PLA was investigated in vitro and the results are given in Figure 5.

Table II. The process conditions and results for preparation of MCN

\begin{tabular}{|c|c|c|c|c|c|c|c|c|}
\hline \multirow{3}{*}{$\begin{array}{l}\text { Test } \\
\text { No. }\end{array}$} & \multirow{3}{*}{$\frac{\text { Solvent }}{\mathrm{v} / \mathrm{v}}$} & \multirow{3}{*}{$\frac{\text { Temp }}{{ }^{\circ} \mathrm{C}}$} & \multirow{3}{*}{$\frac{\text { Time }}{\mathrm{h}}$} & \multicolumn{5}{|c|}{ Results } \\
\hline & & & & \multirow{2}{*}{$\begin{array}{c}\begin{array}{c}\text { Drug } \\
\text { load }\end{array} \\
\frac{\%}{\%}\end{array}$} & \multirow{2}{*}{ Shape } & \multirow{2}{*}{$\frac{\text { Size }}{\mu \mathrm{m}}$} & \multirow{2}{*}{$\begin{array}{c}\text { Recovery } \\
\text { of MCN }\end{array}$} & \multirow{2}{*}{$\begin{array}{l}\begin{array}{l}\text { Per cent of drug } \\
\text { enclosed in MCN }\end{array} \\
\%\end{array}$} \\
\hline & & & & & & & & \\
\hline A-1 & Benzone & 10 & 27 & 10.2 & Sphere & $40-500$ & 73.4 & 48.2 \\
\hline A-2 & $\begin{array}{l}\text { Acetone-chloroform } \\
\qquad(4: 6)\end{array}$ & 10 & 24 & 19.5 & Granule & - & 91.8 & 92.9 \\
\hline A-15 & $\begin{array}{l}\text { Acetone-chloroform } \\
\qquad(3: 7)\end{array}$ & 20 & 11 & 19.8 & Sphere & $40-400$ & 86.2 & 94.3 \\
\hline A-5 & $\begin{array}{c}\text { Acetone-chloroform } \\
\qquad(3: 7)\end{array}$ & 35 & 5 & 20.1 & Granule & $40-400$ & 90.4 & 95.2 \\
\hline C-05 & $\begin{array}{c}\text { Acetone-chloroform } \\
(3: 7)\end{array}$ & 10 & 30 & 19.7 & Sphere & $40-300$ & 92.2 & 93.8 \\
\hline C-06 & $\begin{array}{c}\text { Acetone-chloroform } \\
\qquad(3: 7)\end{array}$ & 10 & 30 & 19.8 & Sphere & $40-400$ & 89.6 & 94.3 \\
\hline C- 02 & $\begin{array}{c}\text { Acetone-chloroform } \\
(3: 7)\end{array}$ & 10 & 30 & 19.7 & Sphere & $40-400$ & 91.4 & 93.8 \\
\hline
\end{tabular}
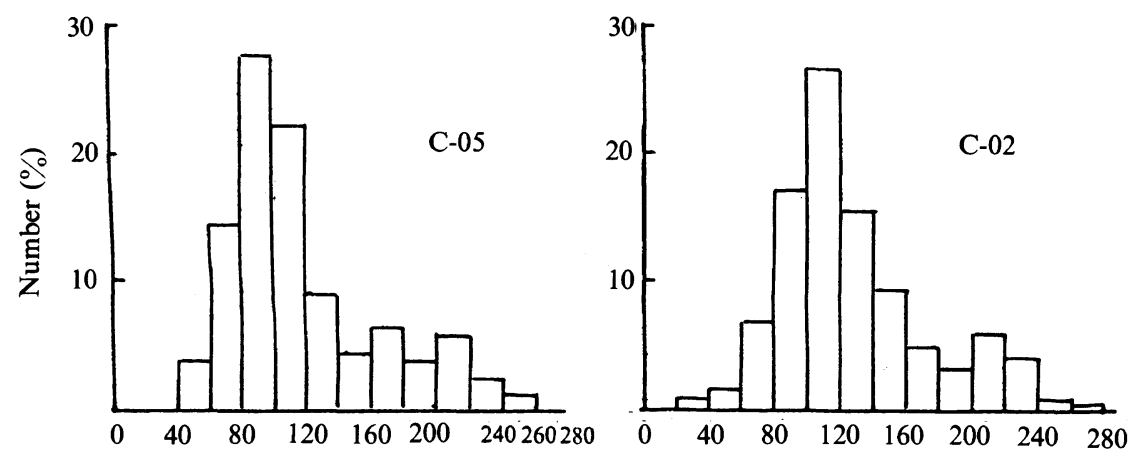

Diameter $(\mu \mathrm{m})$

Figure 2. Size distribution of the MCN. 
As mentioned above, the diblock copolymer of PCL- $b$-PLA would show an controllable variability in response to the ratio of $\mathrm{CL} / \mathrm{LA}$.

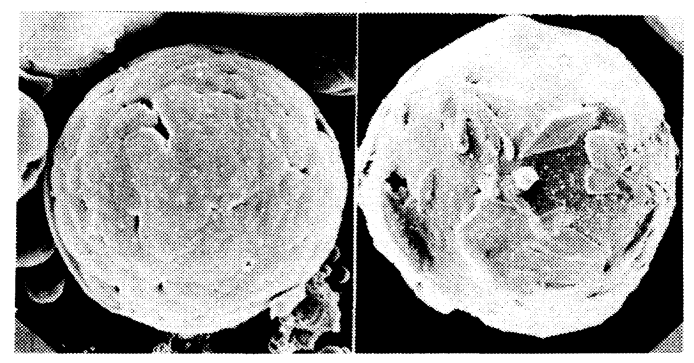

(a) $400 \times$

(b) $400 \times$

Figure 3. Scanning electron micrograph of $\mathrm{MCN}$ prepared at (a), $20^{\circ} \mathrm{C}$ and (b), $35^{\circ} \mathrm{C}$.
PCL- $b$-PLA would show an controllable variability in response to the ratio of CL/LA. From Figure 5 we can see that although all the samples would maintain a sustained release for at least 6 months, they represent quite different rates and kinetics for microspheres of different composition. Line C-02 in Figure 5 shows the daily release of Norgestrel from $\mathrm{MCN}$ composed of $90 \% \mathrm{CL}$ and $10 \% \mathrm{LA}$, which shows a declining rate with time like what has been seen with PCL homopolymer microsphere. Its percent release amount is linearly proportional to the square root of time which suggested a first-order kinetics (see Figure 6).

On the contrary, the MCN composed of

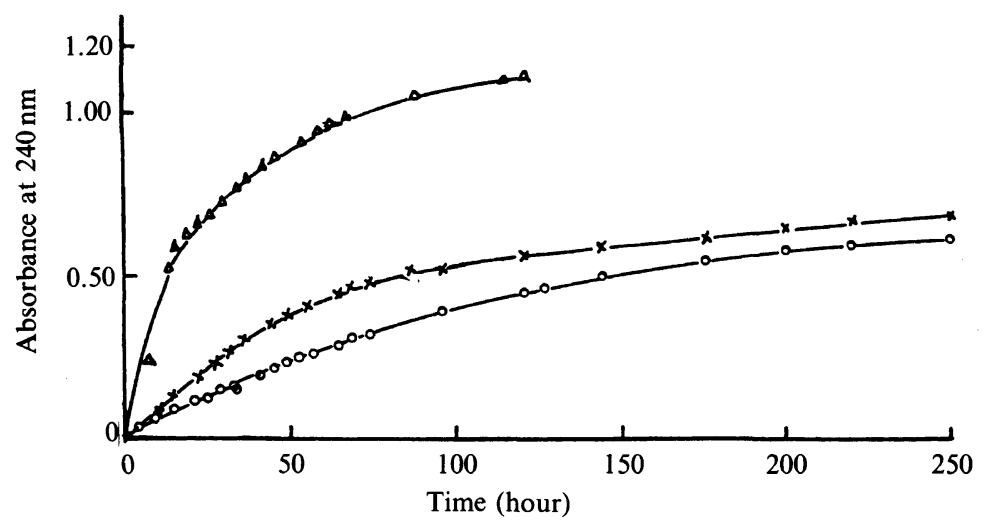

Figure 4. Comparison of release rate of Norgestrel from $\mathrm{MCN}$ prepared at different temperatures in $20 \% \mathrm{EtOH}$ at $37^{\circ} \mathrm{C} . \triangle-\triangle, \mathrm{MCN}$ of $35^{\circ} \mathrm{C} ; \times-\times, \mathrm{MCN}$ of $20^{\circ} \mathrm{C} ; \mathrm{O}-\mathrm{O}, \mathrm{MCN}$ of $10^{\circ} \mathrm{C}$.

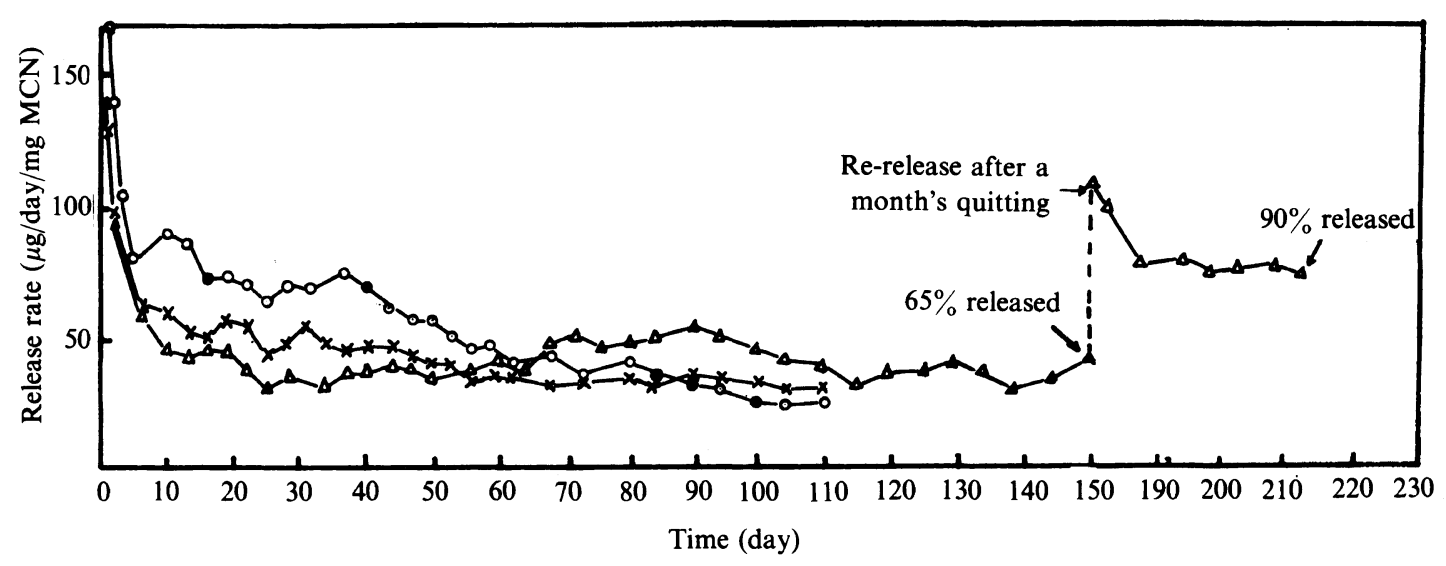

Figure 5. Daily release of Norgestrel from PCL- $b$-PLA microspheres with different segment ratio of $\mathrm{CL} / \mathrm{LA}$, in vitro, at $37^{\circ} \mathrm{C}$. $\mathrm{O}-\mathrm{O}, \mathrm{C}-02 ; \times-\times, \mathrm{C}-06 ; \triangle-\triangle, \mathrm{C}-05$. 


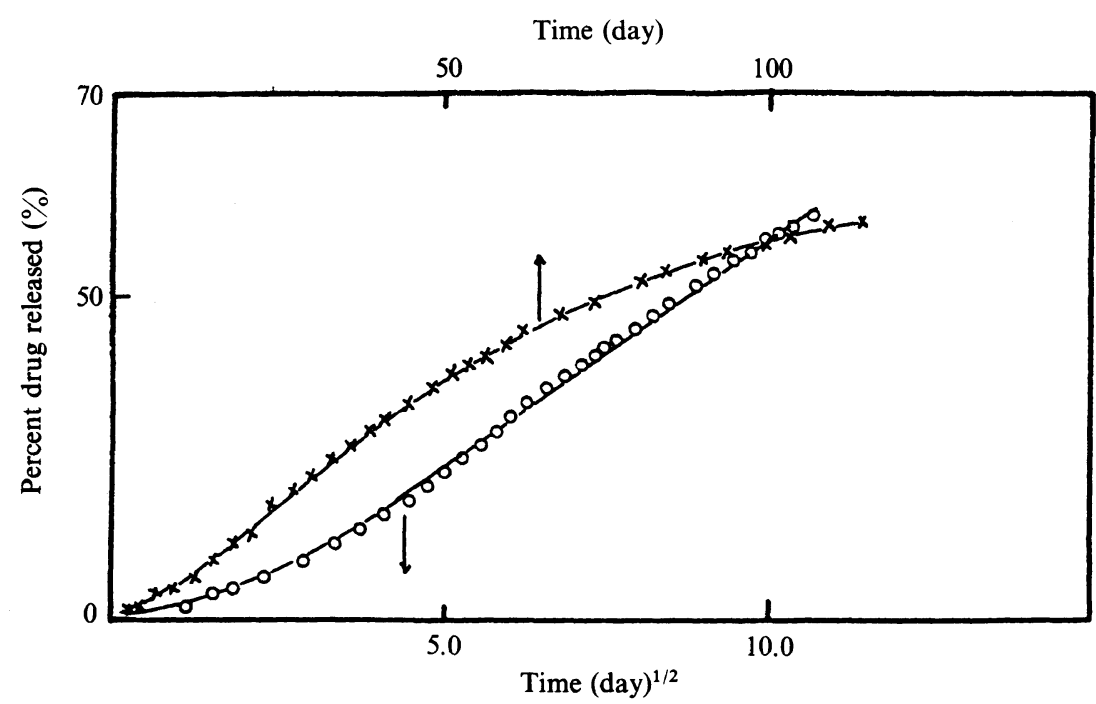

Figure 6. Cumulative release of Norgestrel from microsphere of PCL- $b$-PLA with $90 / 10$ of CL/LA, in vitro, $37^{\circ} \mathrm{C}$.

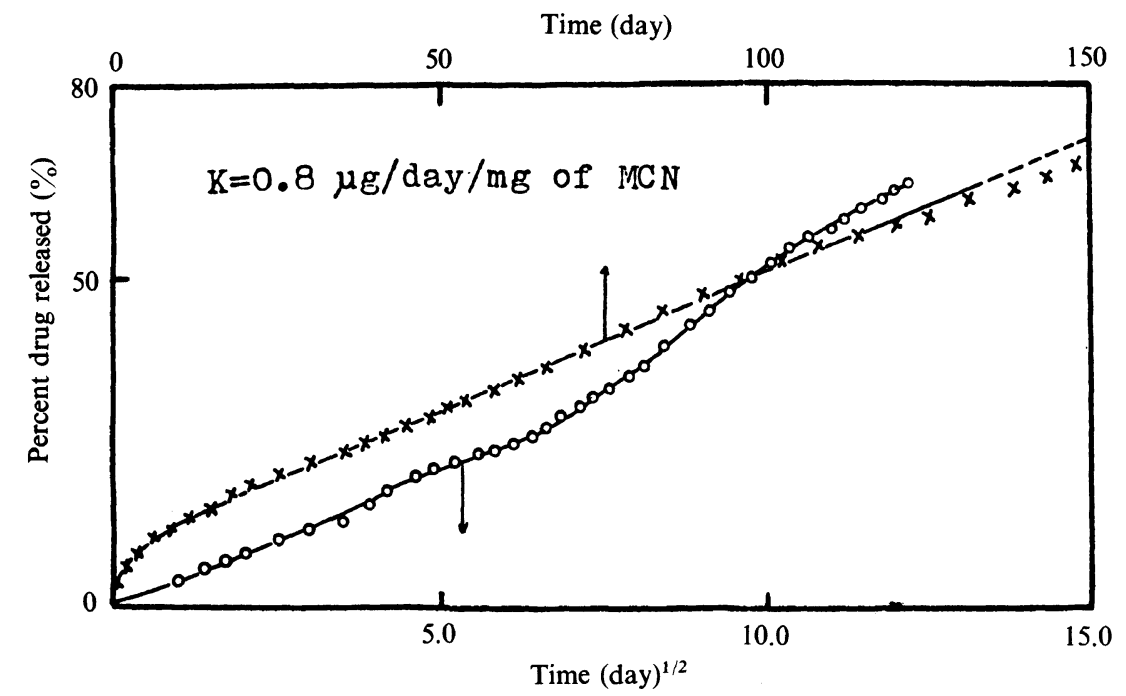

Figure 7. Cumulative release of Norgestrel from microsphere of PCL-b-PLA $60 / 40$ of CL/LA, in vitro, $37^{\circ} \mathrm{C}$.

$60 \%$ PCL and $40 \%$ PLA (line C-05) shows almost a constant release for about 4 months without decline. Its percent release amount has almost a linear relationship with the one power of time, which showed a zero-order kinetics (see Figure 7). The rate constant was worked out to be $0.8 \mu \mathrm{g} / \mathrm{day} / \mathrm{mg}$ of $\mathrm{MCN}$ at $37^{\circ} \mathrm{C}$. It is supposed that using $100 \mathrm{mg}$ of $\mathrm{MCN}$ could provide a daily dosage of $80 \mu \mathrm{g}$ for at least 4 months with single injection. The microsphere with $75 / 25$ of CL/LA shows a middle release pattern between the other two extremes as shown in Figure 5 and Figure 8.

It is interesting to notice that the overall release kinetics has changed from first-order to zero-order when PLA segment ratio in the 


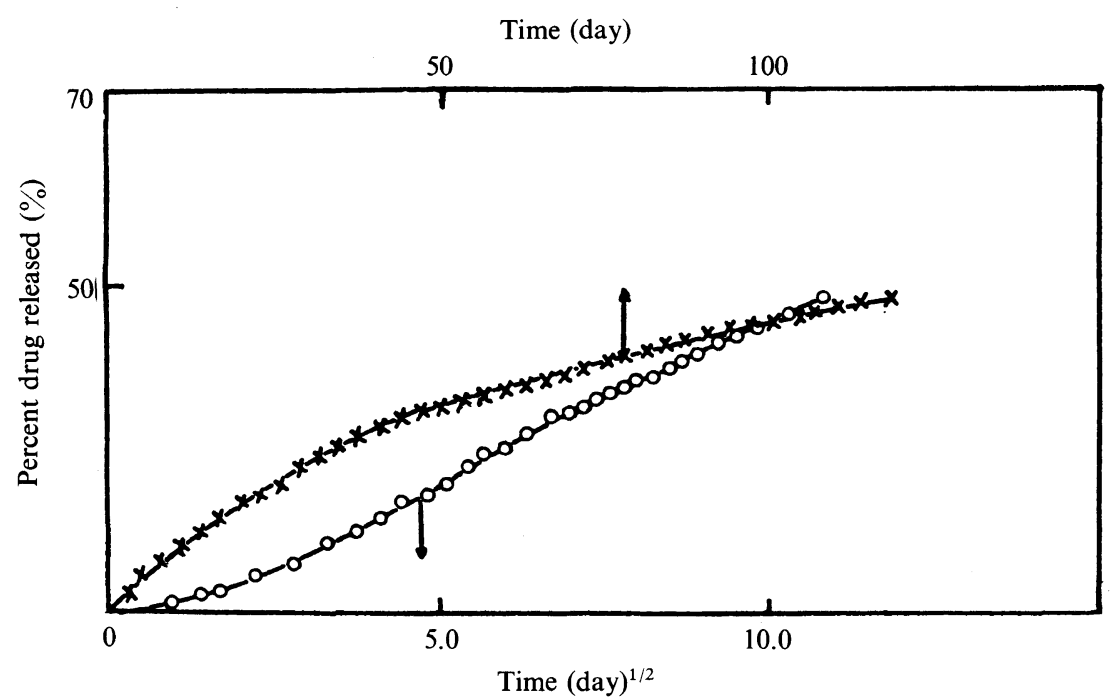

Figure 8. Cumulative release of Norgestrel from microsphere of PCL- $b$-PLA with $75 / 25$-of CL/LA, in vitro.
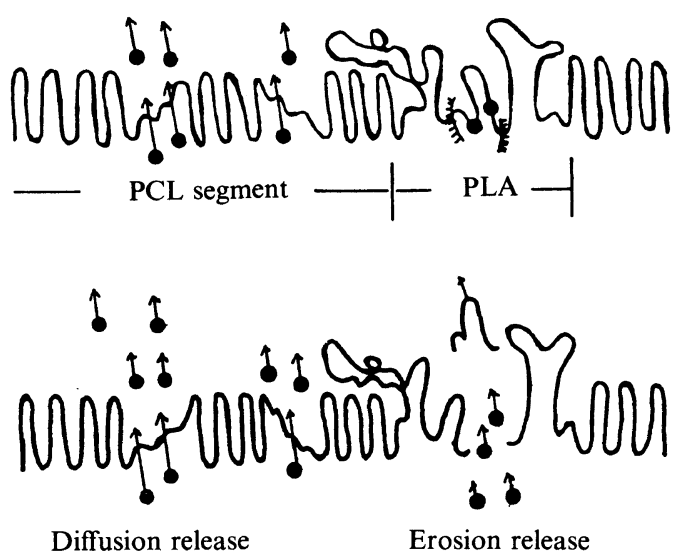

Figure 9. Schematic diagram of release mechanism for PCL- $b$-PLA.

block copolymer increases from $10 \%$ to $40 \%$. This behavior may be attributed to the microphase separation morphology in PCL- $b$ PLA. As shown in Figure 9, the PCL segment in the block copolymer exists as semicrystalline phase like PCL homopolymer which bears higher diffusion coefficient for most steroids but lower degradation rate. So the PCL segment mainly contributes the diffusion-controlled release which results in the first-order kinetics just like that of PCL homopolymer. On the other hand, the PLA segment in the block copolymer would maintain its amorphous state like PLA homopolymer which degradates much more rapidly than PCL segment. As a result, the degradation rate of PCL- $b$-PLA inevitably dependent on the ratio of CL/LA, i.e., increases with increasing PLA ratio. The degradation of PLA segment would result in an additional release, erosion-caused release, and would enhance drug release by leaving holes after some degradation. These effects would act as a good compensation for the rate decline resulted from PCL controlled diffusion release. By varying the ratio of PCL/PLA in the block copolymer, these two release pathways, diffusion and erosion, can be balanced to such an extent that the erosion-caused release could just compensate the declined amount in diffusion release and an overall zero-order release is actually achieved.

\section{CONCLUSION}

1. The block copolymer of $\varepsilon$-caprolactone and DL-lactide (PCL- $b$-PLA) is versatile in 
controlling its biological functions such as biodegradation rate and drug release rate. By altering the ratio of $\mathrm{CL} / \mathrm{LA}$ it is possible to predestine these properties to meet the precise needs for biodegradable and controlled drug delivery device.

2. The microsphere made of PCL- $b$-PLA showed a double release mechanism with a controllable manner. The effects of two pathways can be balanced by tailoring the CL/LA ratio to such an extent that a whole zeroorder release can be achieved.

3. For Norgestrel-containing microsphere some better balance can be accomplished when the ratio of $60 / 40$ is used. It presents a constant release period of around 4 months or more which proved to be a promising controlled delivery system for contraceptives.

\section{REFERENCES}

1. T. M. Jackaniz, N. A. Nash, D. L. Wise, and B. Gregory, Contraception, 8(3), 277 (1973).

2. S. Yolles, T. Leafe, M. Sartori, M. Torkelson, and L. Ward, "Controlled Release Polymeric Formulations," D. R. Paul and F. W. Harris, Ed., ACS Symp. Ser., No. 33, 1977, pp 123-134.

3. L. R. Beck, D. R. Cowsar, D. H. Lewis, J. W. Gibson, and C. E. Flowers, Am. J. Obstet, Gynecol., 135, 419 (1979).

4. K. R. Sidman, A. D. Schwope, W. D. Steber, S. E. Rudolph, and S. B. Poulin, J. Membrane Science, 7, 277 (1980).

5. C. G. Pitt, D. Christensen, R. Jeffcoat, G, L. Kimmel, A. Schindler, M. E. Wall, and R. A. Zweidinger, "Proceedings: Drug Delivery System," L. H. Gabelnick Ed., DHEW Publication No. (NIH) 77: 1238, Baltimore, M.D., 1977, pp 142-192.

6. C. X. Song and X. D. Feng, Polym. Commun. (China), 3, 177 (1983).

7. C. X. Song and X. D. Feng, Macromolecules, 17, 2764 (1984). 